Research Article

\title{
Myocardial salvaging effects and mechanisms of metformin in experimental diabetes
}

\author{
Manjusha K. Borde ${ }^{1}$, Ipseeta Ray Mohanty ${ }^{1}$, Ujwala Maheshwari ${ }^{2}$, Rajesh Kumar Suman ${ }^{1}$, \\ Y. A. Deshmukh ${ }^{1}$
}

${ }^{1}$ Department of Pharmacology, MGM Medical College, Kamothe, Navi Mumbai 410209, India,

${ }^{2}$ Department of Pathology, MGM Medical College, Kamothe, Navi Mumbai 410209, India

Received: 14 January 2016

Accepted: 09 February 2016

*Correspondence to:

Dr. Rajesh Kumar Suman, Email: rajeshsuman2043@ gmail.com

Copyright: () the author(s), publisher and licensee Medip Academy. This is an openaccess article distributed under the terms of the Creative Commons Attribution NonCommercial License, which permits unrestricted noncommercial use, distribution, and reproduction in any medium, provided the original work is properly cited.

\begin{abstract}
Background: Several epidemiological studies have found that in type II diabetic patients, Metformin improves vascular function and reduces cardiovascular events and mortality by mechanisms that are not entirely attributed to its anti- hyperglycemic effects; So far the effect of Metformin on experimentally induced myocardial infarction in setting of type II diabetic rats has not been studied. The aim of the present study was to investigate potential cardioprotective effects and mechanisms of Metformin subsequent to isoproterenol induced myocardial infarction in the setting of diabetes.

Methods: Diabetes was induced with single dose of Streptozotocin (STZ): $45 \mathrm{mg} / \mathrm{kg}$ ip and myocardial infarction was produced by administering isoproterenol (ISP): $(85 \mathrm{mg} / \mathrm{kg}, \mathrm{sc})$ to rats 24 and $48 \mathrm{~h}$ prior to sacrification (5th week). After the confirmation of diabetes on 7 th day (Glucose $>200 \mathrm{mg} / \mathrm{dl}$ ), Metformin $(100 \mathrm{mg} / \mathrm{kg})$ was administered and various parameters like antidiabetic (Glucose, HbA1c), cardioprotective (CPK-MB, hs-CRP), metabolic (lipid profile, artherogenic potential), antioxidant (MDA) safety \{pancreatic function (lipase), liver function (SGPT), kidney function (Creatinine) and histopathological indices of injury were evaluated in experimental groups.

Results: Administration of STZ-ISP resulted in a significant decrease in body weight $(\mathrm{p}<0.001)$, diabetic changes (increase in blood glucose, HbA1c), cardiac injury (leakage of myocardial CPK-MB), altered lipid profile, antiinflammatory, antioxidant, lipase, SGPT, creatinine levels $(p<0.01)$ in the Diabetic- ISP Control group rats as compared to Normal Control. Metformin $(100 \mathrm{mg} / \mathrm{kg})$ treatment demonstrated significant antidiabetic as well as myocardial salvaging effects as indicated by restoration of blood glucose, HbA1c and CPK-MB levels $(p<0.001)$ compared to Diabetic- ISP Control group. In addition, Metformin favorably modulated the lipid parameters (total cholesterol, triglycerides, HDL, LDL), artherogenic index; antioxidant (MDA) potential, Subsequent to ISP challenge, histopathological assessment of heart, pancreas and biochemical indices of injury confirmed the cardioprotective effects of Metformin $(100 \mathrm{mg} / \mathrm{kg})$ in setting of diabetes.

Conclusions: The present study concluded that Metformin at $100 \mathrm{mg} / \mathrm{kg}$ demonstrated myocardial salvaging effects in type II diabetic rats challenged with experimental Myocardial infarction. The antioxidant, hypoglycemic, hypolipidemic and anti-inflammatory effects of Metformin may contribute to its beneficial effects.
\end{abstract}

Keywords: Metformin, Isoproterenol, Streptozotocin, Myocardial infarction, Diabetes

\section{INTRODUCTION}

Diabetes is multifactorial and has been associated with various disorders including obesity, dyslipidemia, thrombosis, infarction, hypertension, endothelial dysfunction, and coronary artery disease. ${ }^{1}$ Diabetes mellitus is a major risk factor for coronary artery disease and is associated with a higher incidence of myocardial infarction and sudden death. ${ }^{2,3}$ Morbidity, mortality and 
re- infarction rate are higher following myocardial infarction in diabetics than non-diabetic subjects. ${ }^{4}$

The multiple systemic disturbances in diabetes result from defective utilization of glucose by cells and the extensive use of alternate energy-generating metabolic pathways. Several considerations explain the wellrecognized association of diabetes with atherosclerosis and myocardial infarction. Experimentally, the changes in hormonal and metabolite levels, enzyme profiles and myocardial histopathology brought about by the administration of isoproterenol, a potent $\beta$-adrenergic stimulating agent, are known to mimic those observed in humans during massive myocardial ischaemia., Isoproterenol can produce an elevated heart rate (tachycardia), which predisposes to cardiotoxicity in animal models. Streptozotocin is a naturally occurring nitrosourea product of streptomyces achromogenes, particularly toxic to the insulin-producing beta cells of the pancreas in mammals resulting in hypoinsulinemia and hyperglycemia. ${ }^{7}$

The discovery of Metformin began with the synthesis of galegine-like compounds derived from Gallega officinalis, a plant traditionally employed in Europe as a drug for diabetes treatment for centuries. In 1950, Stern et al. discovered the clinical usefulness of Metformin related to its glucose lowering capacity and that Metformin toxicity also displayed a wide security margin. ${ }^{8}$ Metformin's efficacy, safety profile, benefit to cardiovascular and metabolic effects, and its capacity to be associated with other antidiabetic agents makes this drug the first glucose lowering agent of choice when treating patients with type II diabetes mellitus. ${ }^{9,10}$ Several epidemiological studies have found that in type II diabetic patients, Metformin improves vascular function and reduces cardiovascular events and mortality by mechanisms that are not entirely attributed to its antihyperglycemic effects. ${ }^{11}$ Charlon $\mathrm{V}$, et al reported that oral administration of Metformin could reduce infarct size in rats, $48 \mathrm{~h}$ after coronary artery ligation. Solskov, et al reported that single dose of metformin $(250 \mathrm{mg} / \mathrm{kg}$ orally) $24 \mathrm{~h}$ before coronary occlusion reduced infarct size in a rat in Langendorff isolated perfused heart model. $^{12,13}$

Till date the effect of Metformin on experimentally induced myocardial infarction in setting of type II diabetic rats has not been studied. The aim of the present study was to investigate potential cardioprotective effects and mechanisms of Metformin subsequent to isoproterenol induced myocardial infarction in the setting of diabetes mellitus.

\section{METHODS}

\section{Experimental animals}

Adult male Wistar rats, 10 to 12 weeks old, weighing 150 to $200 \mathrm{gm}$ were used in the study. Rats were housed in the Animal Facility of Mahatma Gandhi Mission Medical College, Navi Mumbai, Indiain polyacrylic cages $(38 \times 23 \times 10 \mathrm{~cm})$ under standard laboratory conditions. The study protocol was approved by the Institutional Animal Ethics Committee and conforms to the Committee for the Purpose of Control and Supervision of Experiments on Animals and Indian National Science Academy and Guidelines for the Use and Care of Experimental Animals in Research. The animals were allowed free excess to standard diet, tap water ad libitum and allowed to acclimatize for one week before the experiments.

\section{Chemicals and drugs}

Streptozotocin (STZ) and Isoproterenol (ISP) were procured from Sigma Chemicals St Louis, USA. The test drug Metformin was obtained as gift sample from Sonafi pharmaceuticals. All other chemicals and reagents used were of analytical grade.

\section{Experimentally induced myocardial infarction in setting of Type II diabetes mellitus}

Male Wistar rats weighing 150-200 gm was used for the study. Rakieten, et al reported the diabetogenic activity of the compound streptozotocin (STZ). ${ }^{7}$ STZ is specifically cytotoxic to beta- cells of the pancreas. Type II Diabetes was induced in rats by a single STZ injection $(45 \mathrm{mg} / \mathrm{kg}$ body wt, i.p .dissolved in $0.01 \mathrm{M}$ citrate buffer, $\mathrm{pH} 4.5$ ) in overnight fasting rats. Serum glucose estimations were undertaken periodically (day $0,3,7$ ) from the tail vein to confirm the production of diabetes mellitus. Animals showing fasting blood glucose higher than $200 \mathrm{mg} / \mathrm{dl}$ were considered as diabetic and used for the further study. Myocardial infarction was produced by Isoproterenol $(85 \mathrm{mg} / \mathrm{kg}$ dissolved in saline) injection sc 24 and $48 \mathrm{~h}$ prior to scarification (5thweek). At the end of experimental period, rats were sacrificed, blood sample were collected for further biochemical investigation and histopathological evaluation.

\section{Experimental groups}

Group 1: Normal Control (NC): In Normal Control group, rats were administered distilled water per orally using a feeding cannula for study period of 5 weeks.

Group 2: Diabetic ISP Control (D-ISP): The Streptozotocin $(45 \mathrm{mg} / \mathrm{kg}$ body wt, i.p. dissolved in 0.01 $\mathrm{M}$ citrate buffer, $\mathrm{pH} 4.5)$ was injected ip to induce diabetes at 0 week and challenged with Isoproterenol (85 $\mathrm{mg} / \mathrm{kg}$ body wt sc dissolved in saline) 24 and $48 \mathrm{~h}$ prior to scarification $\left(5^{\text {th }}\right.$ week $)$.

Group 3: Metformin (Met): Metformin (100 mg/kg) was fed orally from $1 \mathrm{st}$ to 5 th week (4 weeks). The Streptozotocin $(45 \mathrm{mg} / \mathrm{kg}$ body wt, i.p. dissolved in 0.01 $\mathrm{M}$ citrate buffer, $\mathrm{pH}$ 4.5) was injected ip to induce diabetes at 0 week. Subsequently the rats were challenged 
with Isoproterenol $(85 \mathrm{mg} / \mathrm{kg}$ body wt sc dissolved in saline) 24 and $48 \mathrm{~h}$ prior to scarification (5thweek).

\section{Evaluation parameters}

1. Assessment of body weight changes

Each rat was weighed individually twice, first at the beginning of the experiment (initial weight) and second, 24h after the administration of the last dose of either drug (final weight). The difference in body weight of each rat was calculated and expressed as percentage change according to the following:

$\%$ change in body weight $=$ Final weight - Initial weight X 100/Initial weight

2. Biochemical Parameters

The rat blood samples of all experimental groups were collected from the retro-orbital plexus under light anesthesia at 0,1,3 and 5 weeks for estimation of blood glucose, CPK-MB. In addition, after the completion of the experimental duration (5 weeks), serum was used for the determination of the following parameters like lipid profile, SGPT, Creatinine, hs-CRP by Auto-analyzer or ELISA kits in the Pathology (NABL accredited) and Pharmacology laboratory. MDA was estimated using k. Satoh's method.

3. Histopathological studies

At the end of the experiment (5 weeks), the animals were sacrificed. The heart, liver, kidney and pancreas were immediately fixed in $10 \%$ buffered neutral formalin solution. The tissues was carefully embedded in molten paraffin with the help of metallic blocks, covered with flexible plastic moulds and kept under freezing plates to allow the paraffin to solidify. Cross sections ( $5 \mu \mathrm{m}$ thick) of the fixed tissues were cut. These sections were stained with hematoxyline and eosin and visualized under light microscope to study the microscopic architecture of the tissues. The investigator performing the histological evaluation was blind to biochemical results and to treatment allocation.

\section{RESULTS}

\section{General observations and Assessment of body weight changes}

Diabetic rats, in general, showed classical symptoms of overt diabetes, with signs such as polydipsia, polyphagia and polyurea and after receiving ISP were beset with, within minutes, extremely rapid respiration. The severity of the symptoms became prominent myocardial infarction in setting of Type II diabetes mellitus. The Diabetic-ISP Control group rats showed significant $(p<0.001)$ decrease in body weight $(\%)$ as compared with Normal Control. Metformin $(100 \mathrm{mg} / \mathrm{kg})$ treatment showed significant $(p<0.05)$ decrease in body weight as compared with Diabetic-ISP Control group (Figure 1).

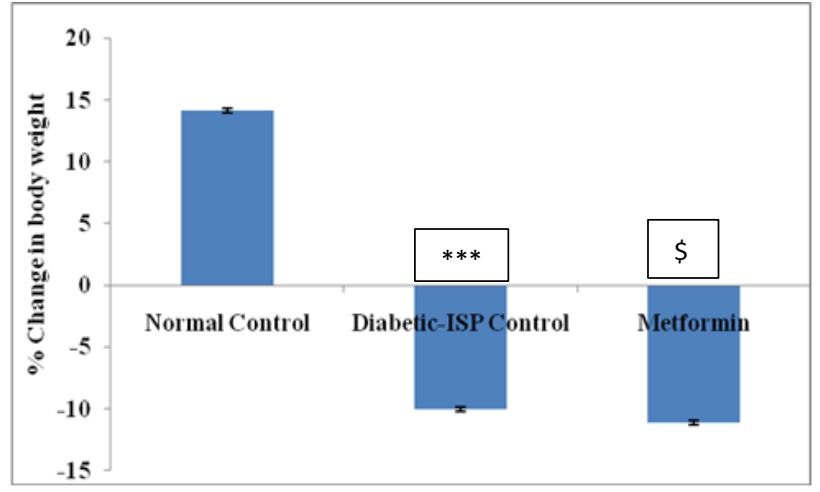

Figure 1: The \% change in body weight of $\mathrm{NC}(\mathrm{n}=8)$, D-ISP group $(n=7)$, Met $(n=7)$. Values are expressed as mean \pm SD. $* * * p<0.001$ NC Vs. D-ISP, \$P<0.05 D-ISP Vs. Met.

\section{Diabetic Parameter}

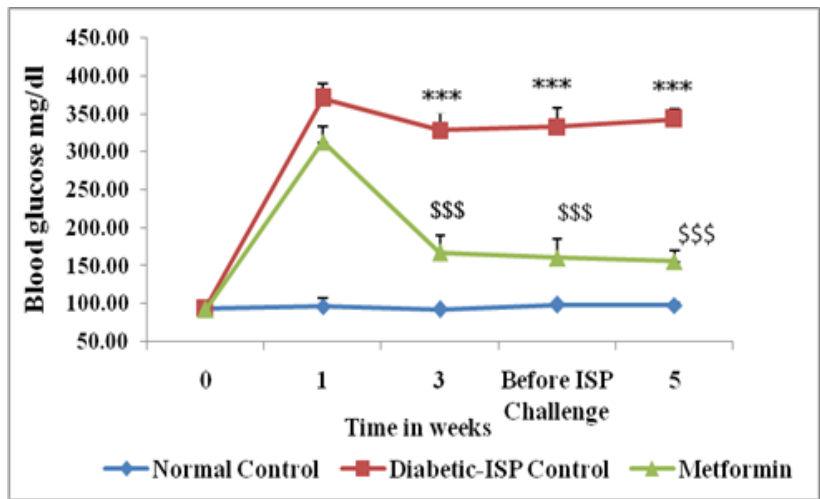

Figure 2: Time course changes of Blood Glucose level of NC $(n=8)$, D-ISP group $(n=7)$, Met $(n=7)$. Values are expressed as mean \pm SD. $* * * p<0.001$ NC Vs D-ISP, \$\$P $<0.001$ D-ISP Vs Met.

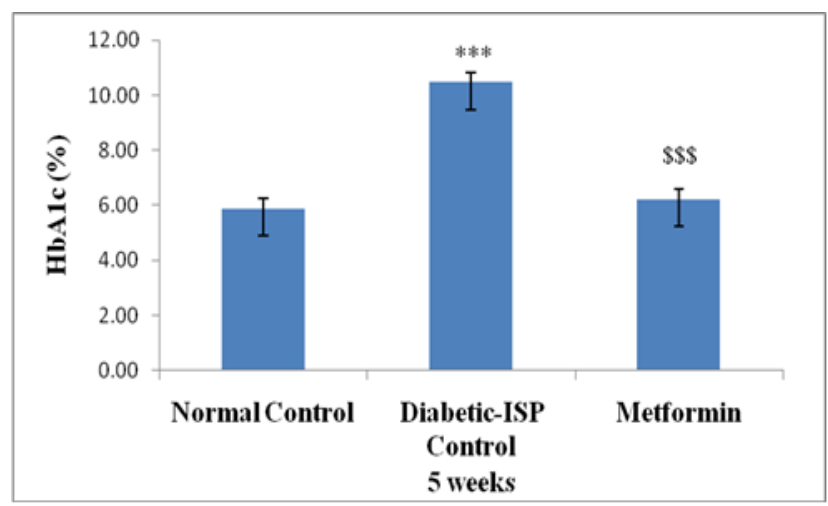

Figure 3: The HbA1c level of NC (n=8), D-ISP group $(n=7)$, Met $(n=7)$. Values are expressed as mean \pm SD. $* * * \mathbf{p}<0.001$ NC Vs D-ISP, \$\$P<0.001 D-ISP Vs Met.

Blood glucose was measured with a glucosemeter. There was a significant $(\mathrm{p}<0.001)$ increase in blood glucose in Diabetic-ISP Control group rats as compared to Normal Control group rats. Oral feeding of Metformin (100 
$\mathrm{mg} / \mathrm{kg})$ significantly restored $(\mathrm{p}<0.001)$ the elevated blood glucose levels. Similarly Glycosylated hemoglobin was also reduced in Metformin $(100 \mathrm{mg} / \mathrm{kg})$ treatment group as compared to the Diabetic-ISP Control rats at 5 weeks (Figure 2 and 3).

\section{Cardiac parameter}

There was a significant $(\mathrm{P}<0.001)$ increase in serum CPK-MB level in Diabetic-ISP Control rats as compared to Normal Control group. Treatment with Metformin $(100 \mathrm{mg} / \mathrm{kg})$ significantly $(\mathrm{P}<0.001)$ reduced elevated serum CPK-MB levels in Metformin treated group as compared to Diabetic-ISP Control group subsequent to ISP challenge. The other cardiac markers hs-CRP was found to be significantly reduced $(\mathrm{p}<0.05)$ in Metformin group as compared with Diabetic-ISP Control group at 5 th week of study after ISP challenge (Figure 4 and Table $2)$.

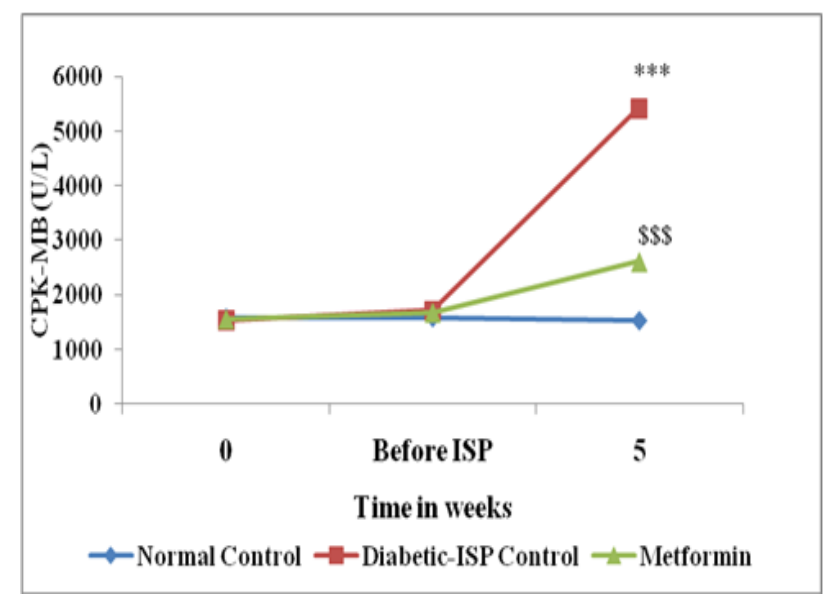

Figure 4: The CPK-MB of NC (n=8), D-ISP group $(n=7)$, Met $(n=7)$. Values are expressed as mean \pm SD. ***p<0.001 NC Vs D-ISP, \$\$P<0.001 D-ISP Vs Met.

\section{Lipid Parameter}

The Diabetic-ISP Control group rats showed significant $(\mathrm{p}<0.001)$ increase in serum TC, TG, LDL and decrease in HDL when compared with Normal Control group of rats. Metformin $(100 \mathrm{mg} / \mathrm{kg})$ treatment significant $(\mathrm{p}<0.001)$ reduced the levels of TC,TG,LDL and increased HDL levels as compared with Diabetic-ISP Control group rats at 5 th week. Diabetic-ISP Control rats displayed the highest level of atherogenic index and were found to be significantly different $(p<0.05)$ from the Normal Control group. The administration of Metformin to diabetic rats after challenge with ISP significantly decreased $(p<0.05)$ these indices as compared with Diabetic-ISP Control group (Table 1).

Table 1: Lipid profile in various experimental groups.

\begin{tabular}{|c|c|c|c|c|}
\hline No. & Variable & NC & D-ISP & Met \\
\hline 1 & $\begin{array}{l}\text { TC } \\
(\mathrm{mg} / \mathrm{dl})\end{array}$ & $67.5+5.08$ & $84.14 \underline{ \pm} 3.71^{* *}$ & $74.28+4.30^{\$}$ \\
\hline 2 & $\begin{array}{l}\text { TG } \\
(\mathrm{mg} / \mathrm{dl})\end{array}$ & $74.14 \pm 4.87$ & $89.71 \pm 3.94^{* * *}$ & $79.14 \pm 5.30^{\$}$ \\
\hline & $\begin{array}{l}\mathrm{HDL} \\
(\mathrm{mg} / \mathrm{dl})\end{array}$ & $32.66 \pm 2.66$ & $23.57 \pm 3.63^{* *}$ & $28.86 \pm 3.31^{\$}$ \\
\hline & $\begin{array}{l}\mathrm{LDL} \\
(\mathrm{mg} / \mathrm{dl})\end{array}$ & $14.83 \pm 0.97$ & $17.94 \pm 0.78^{* *}$ & $15.82 \pm 1.06^{\$}$ \\
\hline & $\begin{array}{l}\text { Atheroge } \\
\text { nic index }\end{array}$ & $1.06 \pm 0.14$ & $2.61 \pm 0.58^{*}$ & $1.57 \pm 0.37^{\$}$ \\
\hline
\end{tabular}

NC $(n=8)$, D-ISP group $(n=7)$, Met $(n=7)$. Values are expressed as mean \pm SD. $* * \mathrm{p}<0.01 * \mathrm{p}<0.05 \mathrm{NC}$ Vs D-ISP, ${ }^{\$} \mathrm{P}<0.01$ D-ISP Vs Met.

\section{Oxidative stress parameter}

The Diabetic-ISP Control group rats showed a significant $(p<0.01)$ increase in the level of Oxidative marker (MDA) when compared to Normal Control group rats at 5 th weeks. The administration of Metformin to diabetic rats subsequent to challenge with ISP significantly decreased MDA levels ( $\mathrm{p}<0.05$ ) as compared with Diabetic-ISP Control group (Table 2).

Table 2: Study variables in the experimental groups.

\begin{tabular}{|lllll|}
\hline No. & Variables & NC & D-ISP & Met \\
\hline 1 & Cardiac Variables Hs-CRP $(\mathrm{mg} / \mathrm{dl})$ & $0.83 \pm 0.15$ & $1.9 \pm 0.5^{* *}$ & $0.93 \pm 0.23^{\$}$ \\
\hline 2 & Oxidative Marker MDA (nmol/ml) & $1.84 \pm 0.07$ & $4.25 \pm 0.18^{* *}$ & $2.75 \pm 0.08^{\$}$ \\
\hline 3 & Pancreatic Marker Lipase (U/L) & $33.33 \pm 2.19$ & $40.13 \pm 5.82^{* *}$ & $34.73 \pm 0.83^{\$}$ \\
\hline 4 & Liver function SGPT (U/L) & $64.12 \pm 2.91$ & $84.54 \pm 2.10^{* *}$ & $68.05 \pm 1.89^{\$}$ \\
\hline 5 & Kidney function Creatinine (mg/dl) & $0.32 \pm 0.06$ & $0.42 \pm 0.03^{* *}$ & $0.35 \pm 0.04^{\$}$ \\
\hline
\end{tabular}

NC ( $=8)$, D-ISP group $(n=7)$, Met $(n=7)$. Values are expressed as mean \pm SD. ${ }^{* *} p<0.01$ NC Vs D-ISP, ${ }^{\$} \mathrm{P}<0.05$ D-ISP Vs Met.

\section{Safety Parameter}

The pancreatic, liver and kidney marker enzymes were analyzed in the different experimental groups. The
Diabetic-ISP Control group rats showed a significant $(\mathrm{p}<0.01)$ increase in the level of Lipase (U/L), SGPT (U/L) and creatinine $(\mathrm{mg} / \mathrm{dl})$ when compared to Normal Control group rats at 5 th weeks. The Metformin 
$(100 \mathrm{mg} / \mathrm{kg})$ treated group did not adversely affect the pancreas, liver and kidney function markers as compared with Diabetic-ISP Control group rats at5th weeks (Table 2).

\section{Histopathological assessment}

\section{a) Histopathology of the heart}

Histopathological assessment of Normal Control group rat heart revealed the non-infracted architecture of the myocardium (Figure 5A). In contrast, the Diabetic-ISP Control group rats subjected to STZ and ISP injury (Figure 5B), demonstrated marked edema, confluent areas of necrosis and separation of myofibers, congested blood vessels and inflammation as compared to the Normal Control group. In the Metformin treatment group rats, occasional focal myofiber loss, inflammation, necrosis and edema was observed. However the degree of edema, inflammation and necrosis was less as compared to the Diabetic-ISP Control group (Figure 5C) (H \& E x 40).
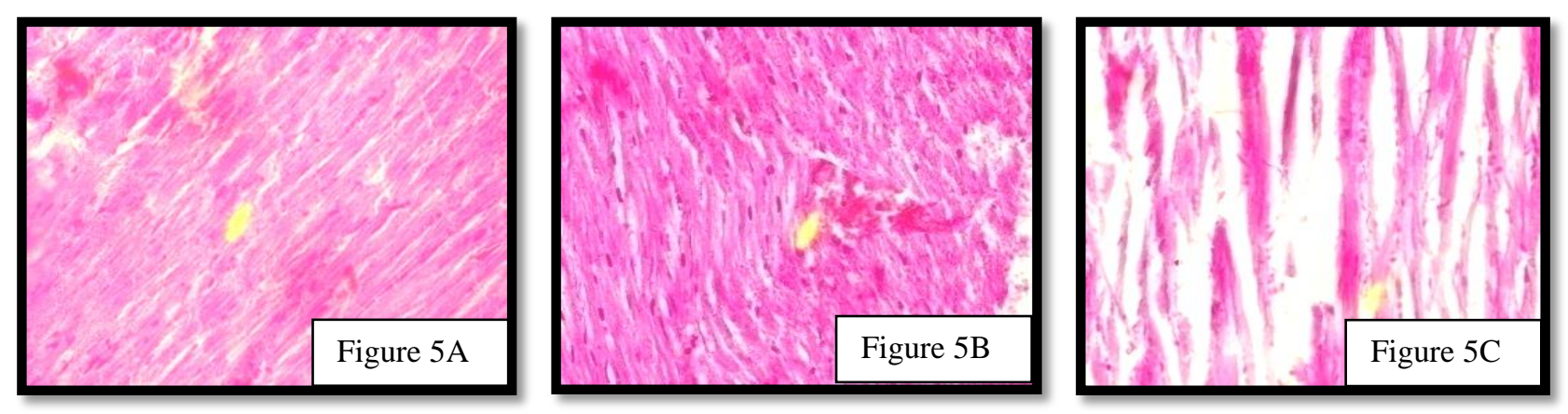

Figure 5: 5A: NC group rat heart revealed the non-infracted architecture of the myocardium. 5B: D-ISP Control group rats subjected to STZ and ISP injury, demonstrated marked edema, confluent areas of necrosis and separation of myofibers, congested blood vessels and inflammation. 5C: Metformin treatment group rats, occasional focal myofiber loss, inflammation, necrosis and edema were observed. However the degree of edema, inflammation and necrosis was less as compared to the Diabetic-ISP Control group (H \& E x 40).
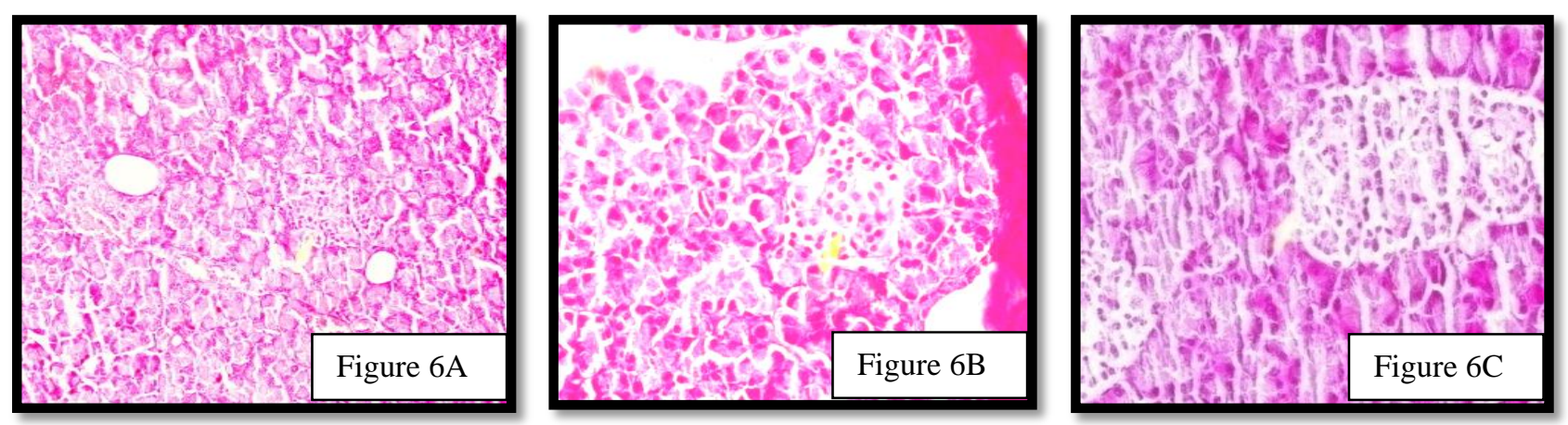

Figure 6: 6A: NC rats pancreas were characterized by an organized pattern and showed normal architecture of islets of langerhans and the beta cells. 6B: D-ISP Control group of rats demonstrated damaged islets of langerhans, atrophy of beta cells and reduced beta cell mass. 6C: Metformin treatment group rats Pancreas shows improve beta cell mass, less inflammatory infiltration and hemorrhage as compared to Diabetic-ISP group (H \& E x 40).

\section{b) Histopathology of the pancreas}

The pancreas of the Normal Control group (Figure 6A) rats were characterized by an organized pattern and showed normal architecture of islets of langerhans and the beta cells. In contrast, the Diabetic-ISP Control group (Figure 6B) of rats demonstrated damaged islets of langerhans, atrophy of beta cellsand reduced beta cell mass as compared to Normal Control. Metformin treatment group rats pancreas showed improved beta cell mass, less inflammatory infiltration and hemorrhage as compared to Diabetic-ISP group (Figure 6C) $(\mathrm{H} \& \mathrm{Ex} 40)$.

\section{c) Histopathology of the liver}

Histological assessment of the liver of the Normal Control group (Figure 7A) rats shows normal 
architecture of central vein, peripheral vein and hepatocytes. In contrast, the liver cells of the DiabeticISP Control group (Figure 7B) showed degeneration, scattered necrotic cells, congestion in the central vein and fat deposition as compared to Normal Control. However Metformin treatment (Figure 7C) decreased the granular degeneration as compared to Diabetic-ISP Control rats. Periportal inflammation hepatocytes degeneration was less compared to Diabetic-ISP Control group. Also no congestion in central vein was observed (H \& E x 40).

\section{d) Histopathology of the kidney}

Histopathology of Normal Control group (Figure 8A) kidney showed absence of congestion of glomerular blood vessels, tubular necrosis and inflammation. In contrast histological assessment of the Diabetic-ISP Control group (Figure 8B) demonstrated congestion of glomerular blood vessels, tubular necrosis, inflammation and cloudy degeneration as compared to Normal Control group. The kidneys of Metformin treated group (Figure 8C) showed congestion of glomerular blood vessels, tubular necrosis, inflammation and cloudy degeneration but it was significantly less as compared to Diabetic-ISP Control group rats.
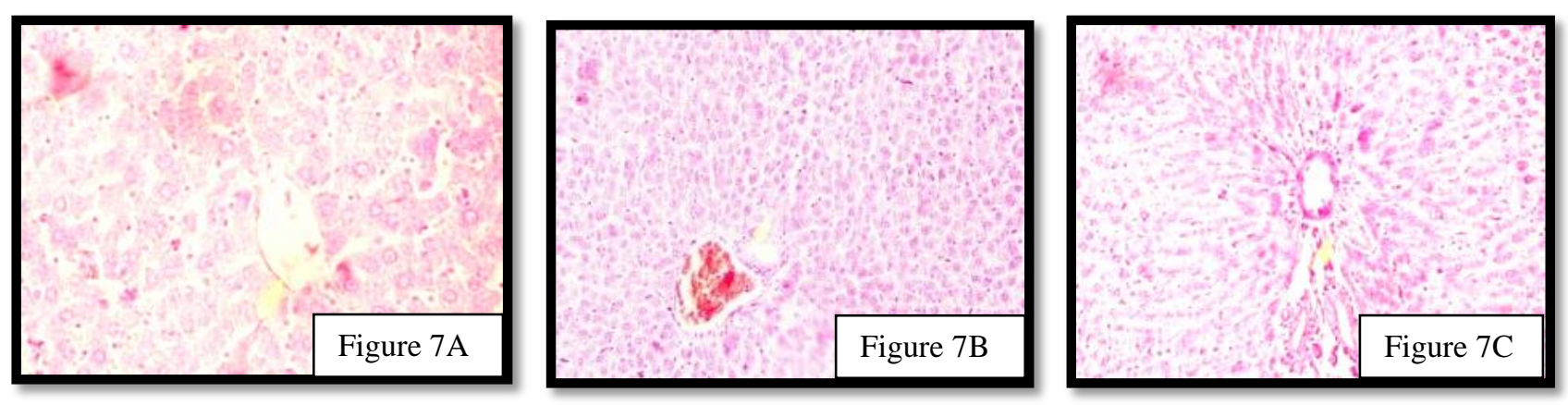

Figure 7: 7A: NC rats liver, shows normal architecture of central vein, peripheral vein and hepatocytes. 7B: D-ISP Control group liver showed degeneration, scattered necrotic cells, congestion in the central vein and fat deposition. 7C: Metformin treated rats liver decrease the granular degeneration in metformin groups compared to DiabeticISP Control rats.
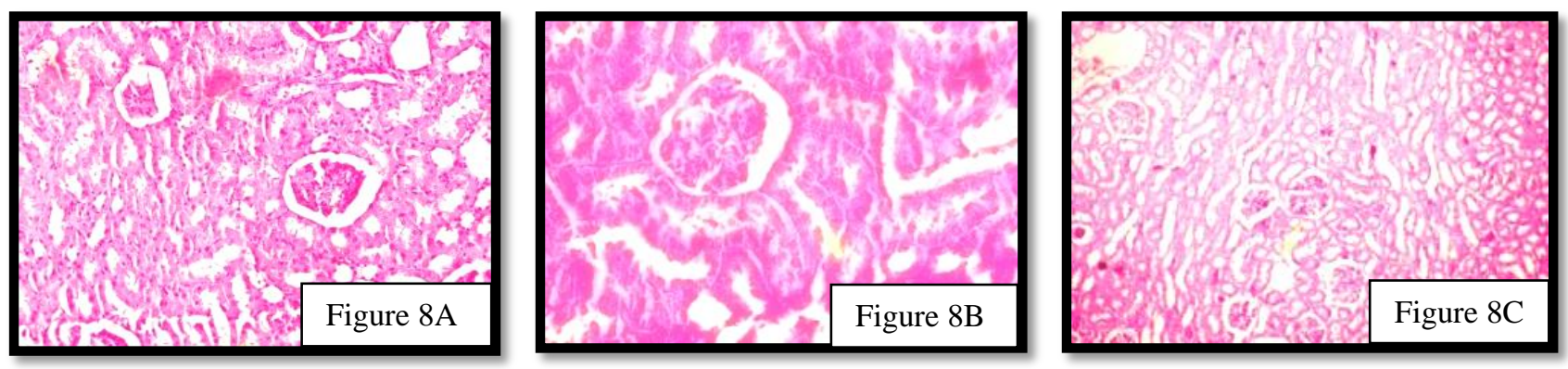

Figure 8: 8A: NC rats kidney showed absence of congestion of glomerular blood vessels, tubular necrosis and inflammation 8B: D-ISP Control group demonstrated congestion of glomerular blood vessels, tubular necrosis,

inflammation and cloudy degeneration. 8C: Metformin treated group of rats kidney showed congestion of glomerular blood vessels, tubular necrosis, inflammation and cloudy degeneration but it was less as compared to Diabetic-ISP Control groups of rats.

\section{DISCUSSION}

The present study was under taken with the objective of exploring the cardio protective effect of Metformin in the setting of diabetes. Several experimental and clinical studies have reported that Metformin possesses cardioprotective effects beyond its glucose-lowering properties. A study by Zhao, et al showed that chronic pre-treatment with Metformin in diabetic patients may reduce noreflow and consequently improve outcome in patients suffering from an acute MI. ${ }^{14}$ However, Metformin's possible cardio protective mechanisms of action beyond glycemic control remain poorly understood. With this point of view the present study has been designed. The cardio protective effect and mechanisms of Metformin in the setting of diabetes has not been explored till date. 
Metformin is recognized as a first-line antidiabetic agent for the management of type II diabetes. It is suitable irrespective of age, body weight, and severity of hyperglycemia and provides a convenient pharmacological base for combined therapy with other antidiabetic agents. ${ }^{15}$ Metformin is renowned to facilitate modest weight loss in type II diabetic patients. ${ }^{(16)}$ In present study Metformin (100 mg/kg) showed significantly decrease in body weight as compared with Diabetic-ISP Control. The study by Poonam Tripathi, et al supported present study that Metformin cause weight loss. $^{17}$

In the present study, an increase in the levels of blood glucose and HbA1c in STZ-ISP treated rats confirmed the induction of diabetes mellitus. The level of HbA1c is monitored as a reliable index of long term glycemic control in diabetes. ${ }^{18}$ Elevated levels of HbA1c observed in our study, reveals that diabetic animals had prior high blood glucose levels. Arshiya Shamim, et al Jagdish Kakadiya, et al showed increase levels of blood glucose in diabetic-ISP rats similar to present study. ${ }^{19,20}$ However, they have not studied Glycosylated hemoglobin. A significant decrease was observed in the glucose and HbA1c levels in diabetic-ISP rats after treatment with Metformin (100 mg/kg) when compared with diabeticISP Control rats at the end of experimental period. Stalin, et al also demonstrated similar results. ${ }^{21}$

Isoproterenol causes significant damage to myocardium, endocardium, hypertrophy and a significant increase in the levels of serum marker enzymes after MI induction. This might be due to the damage in the heart muscle, rendering the leakage of enzymes in to the serum. The biochemical markers that are used widely in detection of myocardial necrosis are CK, LDH and transaminases. CK-MB has greater than $95 \%$ sensitivity and specificity for myocardial injury when measured. Estimation of elevated serum CPK-MB serves as a useful guide for necrosis of myocardium. The CPK-MB was significantly restored by Metformin treatment in diabetic-ISP rats. Xie $\mathrm{Z}$, et al supported the study that treatment with Metformin can also attenuate the development of diabetic cardiomyopathy in diabetic mice. ${ }^{22}$ The other cardiac markers hs-CRP was measured at $5^{\text {th }}$ week of study and was found to be significantly raised in Diabetic-ISP group as compared with NC. Metformin treatment demonstrated anti-inflammatory effects as it reduced this elevated hs-CRP levels as compared to Diabetic-ISP group.

Several studies have tried to correlate the elevated lipid profile in diabetes to the development of cardiac dysfunction. Lipid abnormalities associated with diabetes may lead to alterations in myocardial enzyme systems, subcellular organelles and myocardial fuel supply and eventually to cardiac disease. ${ }^{23}$ Thus alteration in lipid metabolism may be an important determinant of cardiac function in diabetes. In the present study, Metformin showed favourable effects on lipid profile by reducing total cholesterol, triacylglycerols, and LDL levels. In addition Metformin treatment was associated with significant increase in HDL levels as compared to Diabetic-ISP group. Metformin treatment has been reported to improve lipoprotein profiles in diabetic patients by decreasing plasma concentrations of free fatty acid, triglycerides, total cholesterol and LDL cholesterol and by increasing HDL cholesterol. ${ }^{24}$ In addition to its anti-atherogenic effects, Metformin was reported to ameliorate cardiac functional abnormalities in rats with diabetic cardiomyopathy. ${ }^{25}$ In present study decrease in atherogenic index may be due to increase in HDL-C levels after the Metformin treatment. HDL is known to play an important role in the transport of cholesterol from peripheral cells to the liver by a pathway termed reverse cholesterol transport, and is considered to be a cardio protective lipid. The literature shows discrepant results about the influence of Metformin on lipid profile Santana, et al have shown that treatment with Metformin increased HDL level while serum total cholesterol and LDL levels reduced. ${ }^{26,27}$ However, analysis of 29 trials failed to demonstrate significant elevation in HDL levels with Metformin.

Lipid peroxidation was measured by malondialdehyde (MDA), reflects the impact of oxidative stress in cells and tissues. In the present study, MDA concentrations in diabetic rats challenged with ISP were significantly elevated. The increased MDA levels suggest the occurrence of lipid oxidative damage which is implicated in the development of complications of diabetes. Treatment with Metformin significantly reduced the levels of MDA. These finding suggest that Metformin exhibit anti-peroxidative effect. Similar report were shown by Erejuwa, et al in diabetic rat model. ${ }^{28}$

Pancreatic Lipase was assessed to detect pancreatic function and increased Lipase level in D-ISP $(40.13 \pm 5.82)$ as compared to $\mathrm{NC}$, showed damage to pancreatic tissue as compared to NC. SGPT is a hepatic enzyme and biomarker for abnormal liver function. Elevated SGPT levels may also be considered as predictors of DM. ${ }^{29}$ Creatinine concentration is often used as a variable not only to assess impairment of kidney function but also as clinical end point to detect treatment related toxic effects of compounds on the kidney in experimental animals. ${ }^{30}$ Elevated creatinine level is a marker for impaired kidney function in diabetic nephropathy, which was observed in STZ induced diabetic rats. Administration of Metformin improved the pancreatic, liver and kidney function by decreasing the activities of Pancreatic Lipase, SGPT and creatinine in Metformin treated group. Shoba, et al supported liver and kidney injury restoring effects in diabetic rat model. ${ }^{31}$ The effect of Metformin on pancreatic lipase has not been studied before in similar experimental model. 
The present study demonstrates the cardioprotective effects of Metformin in the presence of diabetes mellitus. The hypolipidemic activity, anti-atherogenic effects, antioxidant and anti-inflammatory activities of Metformin contributed to its cardioprotective effects. Myocardial CPK-MB and histopathological findings confirmed the protective effects of Metformin.

\section{CONCLUSION}

The present study concluded that metformin at $100 \mathrm{mg} / \mathrm{kg}$ demonstrated myocardial salvaging effects in type 2 diabetic rats challenged with experimental Myocardial infarction. There may be several mechanisms (favourable lipid profile, reduced artherogenic potential, antiinflammatory, antioxidant) contributing to the cardio protective effects of Metformin.

Funding: No funding sources

Conflict of interest: None declared

Ethical approval: The study was approved by the Institutional Ethics Committee

\section{REFERENCES}

1. Wang J, Song Y, Wang Q, Kralik PM, Epstein PN. Causes and characteristics of diabetic cardiomyopathy. The Review of Diabetic Studies. 2006;3(3):108-17.

2. Kannel WB, Mc Gee DL. Diabetes and cardiovascular disease. The Framingham study. JAMA. 1979;241:2035-8.

3. Fuller JH, Shipley MJ, Rose G, Jarrett RJ, Keen H. Mortality from coronary heart disease and stroke in relation to degree of glycaemia: the White hall study. BMJ (Clin Res Ed). 1983;287:867-70.

4. Ian $1 \mathrm{~W}$, Brian N, Zaman AG. The management of acute myocardial Infarction in patients with diabetes mellitus. The British journal of diabetes and vascular disease. 2003;3(5):319-24.

5. Wexler BC. Metabolic and histopathologic changes in arteriosclerotic versus non arteriosclerotic rats following isoproterenol-induced myocardial infarction with superimposed diabetes.Metabolism. 1975;24(12):1321-37.

6. Bhatt SD, Bora PS, Srivastava LM. Carbohydrates, lipids and lipoproteins and islet changes in diabetes with superimposed myocardial infarction. J. Biosci. 1985;7:387-97.

7. Rakieten N, Rakieten ML, Nadkarni MV. Studies on the diabetogenic action of streptozotocin. Cancer Chemother Rep.1963;29:91-102.

8. Godarzi MO, Brier-Ash M: Metformin revisited: reevaluation of its properties and role in the pharmacopoeia of modern antidiabetic agents. Diabetes Obes Metab. 2005;5:654-65.

9. Radziuk J, Zhang Z, Wiernsperger N, Pye S: Effects of metformin on lactate uptake and gluconeogenesis in the perfused rat liver. Diabetes. 1997;46:1406-13.
10. Nathan DM, Buse JB, Davidson MB, Ferrannini E, Holman RR, Sherwin R et al. American Diabetes Association, European Association for Study of Diabetes: Medical management of hyperglycemia in type 2 diabetes: A consensus algorithm for the initiation and adjustment of therapy: A consensus statement of the American Diabetes Association and the European Association for the Study of Diabetes. Diabetes Care. 2009;32:193-203.

11. Soraya H, Khorrami A, Garjani A, Maleki-Dizaji N, Garjani A. Acute treatment with metformin improves cardiac function following isoproterenol induced myocardial infarction in rats. Pharmacological reports. 2012;64:1476-84.

12. Charlon V, Boucher F, Mouhieddine S, de Leiris J. Reduction of myocardial infarct size by metformin in rats submitted to permanent left coronary artery ligation. Diabetes Metab. 1988;14:591-5.

13. Solskov L, Lofgren B, Kristiansen SB. Metformin induces cardioprotection against Ischaemia/ reperfusion injury in the rat heart $24 \mathrm{~h}$ after administration. Basic Clin Pharmacol Toxicol. 2008;103:82-7.

14. Zhao JL, Fan CM, Yang YJ, You SJ, Gao X, Zhou Q. Chronic pretreatment of metformin is associated with the reduction of the no-reflow phenomenon in patients with diabetes mellitus after primary angioplasty for acute myocardial infarction. Cardiovasc Ther. 2013;31:60-4.

15. Scarpello JHB, Howlett HC. Metformin therapy and clinical uses. Diabetes Vasc Dis Res. 2008;5:157-67.

16. Golay A. Metformin and body weight. Int J Obes. 2008;32:61-72.

17. Tripathi P, Gupta PP, Lal VK. Effect of Coadministration of Allium sativum extract and Metformin on Blood glucose of Streptozotocin induced diabetic rats. J Intercult Ethnopharmacol. 2013;2(2):81-4.

18. Gabbay KH. Glycosylated hemoglobin and diabetic control. New England Journal Medicine. 1976;95:443-54.

19. Shamim A, Mahmood T, Siddiqui HH, Bagga P, Roy S. Effect of Tinosporacordifolia (Guduchi) root extract on cardiotoxicity in streptozotocin induced diabetic rats. Asian Journal of Biomedical and Pharmacutical Sciences. 2015;5(45):12-9.

20. Kakadiya J. Investigate the effect of hesperidin on serum diabetes marker, lipid profile and lipid metabolizing enzymes in experimentally induced myocardial infarction in diabetes in rats International Journal of Biological \& Pharmaceutical Research. 2010;1(1):37-42.

21. Stalin C. Evaluationof antidiabetic activity of methanolic leaf extract of ficus carica in alloxan induced diabeticrats. Asian Journal of Pharmaceutical and Clinical Research.1012;5(3):857.

22. Xie Z, Lau K, Eby B. Improvement of cardiac functions by chronic metformin treatment is 
associated with enhanced cardiac autophagy in diabetic OVE26 mice. Diabetes. 2011;60:1770-8.

23. Rodrigues BH, Xiang, Mc Neill JH. Effect of Lcarnitine treatment on lipid metabolism and cardiac performance in chronically diabetic rats. Diabetes. 37;1988:1358-64.

24. Batchuluun B, Sonoda N, Takayanagi R, Inoguchi T. The Cardiovascular Effects of Metformin: Conventional and New Insights. J Endocrinol Diabetes Obes. 2014;2(2):1035.

25. Verma S, McNeill JH. Metformin improves cardiac function in isolated streptozotocin- diabetic rat hearts. Am J Physiol. 1994;266:H714-9.

26. Santana LF, Sa MF, Ferriani RA, Moura MD, Foss MC, Reis RM. Effect of metformin on the clinical and metabolic assessment of women with polycystic ovary syndrome. Gynecol Endocrinol. 2004;19:8696.

27. Wulffele MG, Kooy A, Zeeuw D, Stehouwer CD, Gansevoort RT. The effect of metformin on blood pressure, plasma cholesterol and triglycerides in type 2 diabetes mellitus: A systematic review J Intern Med. 2004;256:1-14.
28. Erejuwa OO. Glibenclamide or Metformin Combined with Honey Improves Glycemic Control in Streptozotocin-Induced Diabetic Rats. International journal of biological science. 2011;7(2):244-52.

29. Harris EH: Elevated liver function tests in type 2 diabetes. Clin Diabetes. 2005;23:115-9.

30. Travlos GS, Morris RW, Elwell MR, Duke A, Resenblum S, Thompson MB. Frequency and relationships of clinical chemistry and liver and kidney histopathology findings in 13-week toxicity studies in rats. Toxicology.1996;107:17-29.

31. Sobha. Evaluation of antidiabetic potential of nymphaea nouchali burm. F. seeds in stz - induced diabetic rats. International journal of pharmacy and pharmaceutical sciences. 2014;6(4):536-41.

Cite this article as: Borde MK, Mohanty IR, Maheshwari U, Suman RK, Deshmukh YA. Myocardial salvaging effects and mechanisms of metformin in experimental diabetes. Int J Basic Clin Pharmacol 2016;5:341-9. 